\title{
Feinstaubbelastung korreliert mit dem Schlaganfallrisiko
}

\author{
Die Assoziation zwischen den täglichen Veränderungen der \\ Feinstaubbelastung und der kardiovaskulären Morbidität und \\ Mortalität ist gut untersucht. Unklar ist dagegen, ob allgemein \\ als sicher geltende Belastungsgrenzen das Schlaganfallrisiko \\ erhöhen. G. A. Wellentius et al. gingen dieser Frage nun nach. \\ Arch Intern Med 2012; 172: 229-234
}

Die Autoren identifizierten hierzu 1705 Patienten aus dem Großraum Boston in den USA, die zwischen 1999 und 2008 aufgrund eines ischämischen zerebralen Insults in einer Klinik aufgenommen worden waren. Bezüglich der Feinstaubbelastung der Luft wurden die Konzentrationen von Partikeln mit einer Größe $<2,5 \mu \mathrm{m}\left(\mathrm{PM}_{2,5}\right)$ von einer Überwachungsstation kontinuierlich gemessen, die von Sulfatpartikeln täglich von 9-21 Uhr. Außerdem erhielten die Autoren von einer anderen Messstation die stündlichen Werte von Stickoxid, Kohlenmonoxid und Ozon. In der Folge analysierten sie die Assoziation zwischen dem Schlaganfallrisiko und den Feinstaubkonzentrationen in den Stunden und Tagen vor dem Ereignis. Das Durchschnittsalter der Patienten betrug 73,1 Jahre. Ischämien der kleinen Gefäße waren die häufigste Ursache für den Schlaganfall (26\%), gefolgt von Kardioembolien (25\%) und Arteriosklerose der großen Gefäße (20\%); die Krankenhausmortalität lag bei 5,8\%. An 2888 Tagen der Studienperiode (83\%) wurde die Luftqualität von offizieller Seite als gut eingestuft, an 572 Tagen als mäßig. Die Odds Ratio für einen ischämischen Insult nach einer 24-stündigen Periode mit mäßiger Luftqualität betrug 1,34 verglichen mit einer Periode mit guter Luftqualität. Dabei erwies sich die Assoziation zwischen der $\mathrm{PM}_{2,5}$-Konzentration und dem Schlaganfallrisiko als nahezu linear. Betrachtete man die $\mathrm{PM}_{2,5}$-Konzentration als kontinuierliche Variable, betrug die Odds Ratio für einen Insult 1,11. Die $\mathrm{PM}_{2,5}$-Konzentrationen, die weiter als 24 Stunden zurück lagen, waren nicht mit einem höheren Schlaganfallrisiko assoziiert. Der Anstieg des Risikos war am größten innerhalb von 12-14 Stunden nach $\mathrm{PM}_{2,5}$-Exposition und fiel danach wieder ab.

\section{Fazit}

Die Ergebnisse weisen darauf hin, dass eine Feinstaubexposition gegenüber Konzentrationen von $\mathrm{PM}_{2,5}$, die allgemein als sicher gelten, das Risiko für ischämische Insulte innerhalb weniger Stunden erhöhen, so die Autoren.

Dr. Johannes Weiß, Bad Kissingen 